John B. Lowe

\author{
Author's address \\ John B. Lowe \\ Howard Hughes Medical Institute, \\ Department of Pathology, University of \\ Michigan Medical School, Ann Arbor, USA. \\ Correspondence to: \\ John B. Lowe, MD \\ Howard Hughes Medical Institute \\ Department of Pathology \\ University of Michigan Medical School \\ MSRBI, Room 3510 \\ 1150 West Medical Center Drive \\ Ann Arbor \\ MI 48109-0650, USA \\ Fax: 7349361400 \\ e-mail: JohnLowe@Umich.edu \\ Acknowledgements \\ John Lowe is an Investigator of the Howard \\ Hughes Medical Institute. This work was \\ supported in part by NIH grant \\ 1P01CA7 1932. I thank Uli von Andrian for \\ alerting me to the publication cited in [8], \\ and for sharing with me reproductions of \\ figures within it.
}

\section{Glycosylation in the control of selectin counter-receptor structure and function}

Summary: Leukocyte trafficking is characterized by sequential cell adhesion and activation events that deliver specific leukocyte subsets to distinct extravascular locations under different pathophysiological circumstances. E-, P- and/or L-selectin-dependent leukocyte-endothelial cell adhesive interactions contribute essentially to this process. Selectin counterreceptor activity on leukocyte and high endothelial venules is borne by specific glycoproteins whose ability to support adhesion requires specific post-translational modifications. These modifications are typified by serine/threonine-linked oligosaccharides capped with the sialyl Lewis $x$ moiety, an $\alpha 2-3$ sialylated, $\alpha 1-3$ ucosylated tetrasaccharide synthesized by specific glycosyltransferases. Recent advances in glycan structure analysis and in characterizing mice with targeted deletions of glycosyltransferase and sulfotransferase genes discloses an essential role for 6-O GlcNAc sulfate modification of the sialyl Lewis $\mathrm{x}$ tetrasaccharide in L-selectin counter-receptor activity. Related studies identify novel extended Core 1 type O-glycans bearing the 6-sulfosialyl Lewis x moiety, define the molecular nature of the MECA-79 epitope, and disclose a requirement for the $\alpha 1$-3fucosyltransferases FucT-IV and FucT-VII in the elaboration of Lselectin counter-receptor activities. Parallel studies also demonstrate that these 2 fucosyltransferases, a core 2 GlcNAc transferase, and core 2-type sialyl Lewis $\mathrm{x}$ determinants make essential contributions to leukocyte Pselectin counter-receptor activity, and figure prominently in the control of leukocyte E-selectin counter-receptor activity.

\section{Introduction}

The innate and adaptive immune responses are characterized, in part, by cell migration events that have evolved to move specific classes of leukocytes from one place in the body to another (1). These migration events include those that convene polymorphonuclear leukocytes at sites of acute inflammation and that summon mononuclear cells to chronic inflammatory locations. Both processes are characterized by inducible recruitment of blood-borne leukocytes to extravascular sites (2-6). Cell migration events characteristic of the adaptive immune response include those that constitut- 
ively populate secondary lymphoid organs with $\mathrm{B}$ and $\mathrm{T}$ cells $(4,5)$ and that disseminate professional antigen-presenting cells to extravascular, such as the skin (Langerhans cells), and other organs (dendritic cells) (6). Evolution has endowed these processes with potent discriminatory powers to ensure that the proper leukocyte is delivered to the proper site in the proper physiological or pathological context. Imperfections in these processes can lead to qualitatively or quantitatively inappropriate delivery of leukocytes that can incite or perpetuate pathological processes of an inflammatory nature. Such imperfections provide opportunities for developing antiinflammatory pharmacological interventions (7). Regardless of their constitutive or inducible nature, it is intuitive that all such processes must generally share a requirement for adhesion of blood-borne leukocytes or their progenitors to the vascular wall. Intuition in this instance is accompanied by sound experimental observations, initiating as early as the 19th century when drawings of leukocytes rolling in an amphibian vascular bed were published (8). Much subsequent work has culminated in increasingly precise characterizations of the molecules relevant to such processes and how they work.

Experimental efforts to identify and characterize molecules relevant to leukocyte-endothelial cell adhesion may be assigned to two general categories. One of these categories corresponds to members of the integrin family. In the context of leukocyte adhesion and trafficking, the relevant integrins generally localize to the leukocyte, and recognize ligands expressed by the endothelium via protein-protein interactions. Integrin-dependent leukocyte adhesion is reviewed elsewhere (9). The second category of adhesion molecules involved in leukocyte trafficking from the blood to extravascular compartments corresponds to the three members of the selectin family (2). These molecules, termed E-selectin, P-selectin and Lselectin, are type I transmembrane proteins. Each contains an amino terminal domain that exhibits primary sequence similarity to carbohydrate binding proteins. This domain is termed the carbohydrate recognition domain, or CRD; recent advances in understanding the structures of glycan-based ligands whose recognition requires this domain $(2,3)$ and genetic control of their synthesis will be the primary focus of this review.

\section{Selectin-dependent leukocyte recruitment}

Selectin-dependent leukocyte adhesion and recruitment processes (2) can be split into two distinct categories distinguished by whether they are inducible or constitutive, by the type(s) of cell(s) recruited, and by the molecular nature of the corresponding glycan-based counter-receptors. The first category is distinguished by E-, P- and L-selectin-dependent recruitment of neutrophils, monocytes, eosinophils, certain "effector" $T$ lymphocytes and dendritic cells to extravascular sites of acute or chronic inflammation. Recruitment is accompanied by activation-dependent expression of $\mathrm{E}$ - and P-selectin and/or by elaboration of L-selectin ligands, all in temporal and spatial correspondence with the inflammatory circumstance. In the absence of overt inflammation, the endothelium in some vascular beds constitutively expresses low levels of E- and P-selectins (10). By contrast, inflammatory insults are accompanied by robust, transcription-dependent inducible expression of E-selectin, mediated by IL- $1 \beta$, TNF- $\alpha$ and other inflammatory mediators (11). Similarly, P-selectin is also inducibly expressed by vascular endothelium in response to inflammatory mediators, through mechanisms that include transcriptional upregulation and release of preformed P-selectin stored in Weibel-Palade bodies of the endothelial cell (2). P-selectin is also released from preformed stores by activated platelets. E- and P-selectin-dependent leukocyte adhesion under these circumstances is characterized by low affinity recognition of leukocyte-borne selectin counter-receptors whose ligand activities require specific glycan-based post-translational modification $(2,3)$. These low affinity, Eand P-selectin-selectin ligand adhesion couples mediate capture of free-flowing leukocytes by the endothelium, and in the context of vascular shear flow, cause the tethered leukocytes to roll along the E- and P-selectin-bearing endothelial cells that line the vessel lumen. L-selectin, by contrast, is constitutively expressed by most types of circulating leukocytes. L-selectin also mediates low affinity interactions leading to shear-dependent leukocyte rolling, though in contrast to Eand P-selectins, L-selectin recognizes endothelial cell-derived ligands (L-selectin-dependent primary capture of leukocytes) (12), as well as ligands displayed by leukocytes previously adhered to the endothelium (secondary capture) (13).

By contrast, the second category of selectin-dependent leukocyte adhesion and recruitment is substantially more specialized and corresponds to lymphocyte homing, the process whereby the parenchyma of lymph nodes is populated with $\mathrm{T}$ and $\mathrm{B}$ lymphocytes by recruiting them from the circulation $(4,5)$. This process is constitutive, and is without a direct requirement for E- or P-selectins. It is characterized by lowaffinity interactions between lymphocyte-borne L-selectin and specific glycan-based counter-receptors expressed by the plump, specialized endothelial cells (termed high endothelial cells, or HEC) that line the postcapillary venules (termed high 
endothelial venules, or HEV) in secondary lymphoid organs. As in the inflammation-dependent adhesion category, lowaffinity adhesive interactions under shear flow leads to rolling of lymphocytes along the HEV.

In both categories of selectin-dependent leukocyte adhesion, tethered and rolling leukocytes, brought into close physical proximity to the vessel wall, are then subjected to activational stimuli, prominently including chemokines derived from the endothelium, the vascular wall and perivascular structures (14-16). These stimuli, through inside-out signaling events within the leukocyte, lead to activation of the leukocyte integrins $(9,17,18)$. The activated leukocyte integrins in turn enable firm adhesion to integrin counterreceptors expressed by the endothelium (9), leading to chemoattractant-directed emigration of the leukocyte to the extravascular compartment. Specificity in determining which of several rolling leukocyte types should be recruited in any given context is fostered in part by leukocyte type-specific expression of chemokine receptors, and context-specific expression of the corresponding chemokines (14-16). This multistep, multimolecule model for leukocyte recruitment has been reviewed elsewhere $(4,5)$.

While summarizing information about selectin ligand structure, synthesis and control that has been reviewed in detail previously $(2,3)$, this article will include a focus on recent advances in understanding the genes, molecules and events that characterize a) glycan-based, HEV-expressed L-selectin counter-receptors required for lymphocyte homing and b) glycan-based, leukocyte-borne E-, P-selectin counter-receptors required for inflammation-dependent leukocyte recruitment. Much of this work has involved genetic manipulation of glycosyltransferase loci and glycosylation phenotypes in cultured animal cells or in experimental mice. Some issues relevant to glycan synthesis will therefore be presented first to help the reader more fully appreciate experimental evidence supporting roles for specific genes and glycan structures in contributing to selectin counter-receptor activity.

\section{General principles of glycosylation in mammals}

The electronic microscope discloses an osmophilic, electrondense frosting on the surfaces of essentially all mammalian cells when those cells are stained with ruthenium red, a cationic dye with affinity for acidic polymers (containing sialic acid, hyaluronic acid and sulfate, for example) (19). This layer is termed the glycocalyx. It is estimated to have a thickness of between 20 and 110 nanometers (reviewed in 20), corresponds to the oligosaccharide-rich post-translational modifications covalently attached to membrane-associated proteins and lipids (reviewed in (21)), and represents a prominent surface entity through which the cell interacts with its environment. The components of the glycocalyx represent specific classes of glycoconjugates, including asparagine-linked glycans (N-glycans), serine/threonine-linked glycans (O-glycans), lipid-linked glycans (glycolipids) and proteoglycans. It will be apparent from the discussion below that specific types of O-glycans figure prominently in the display of selectin ligand activities that contribute essentially to leukocyte trafficking events.

Mammalian glycoconjugates, including those that contribute to selectin ligand activity, represent linear and branching polymers composed of a limited repertoire of monosaccharides linked via glycosidic bonds in numerous yet specific ways. As reviewed elsewhere (21), the combinatorial possibilities enabled by linking several different monosaccharides through several different glycosidic configurations are enormous. Although not all such combinatorial possibilities are realized in nature, within any given species hundreds of distinct glycan structures exist. Assembly of these glycoconjugates is catalyzed primarily by enzymes called glycosyltransferases (22). These enzymes are generally type II transmembrane proteins composed of a short $\mathrm{NH} 2$-terminal domain that localizes to the cytosol, a single membrane-spanning domain, and a larger $\mathrm{COOH}$-terminal catalytic domain localized to the lumen of the Golgi apparatus (Fig.1). With rare exception, each glycosyltransferase uses only one of several sugar nucleotide substrates (GDP-fucose, GDP-mannose, UDP-galactose, UDP-glucose, UDP-N-acetylgalactosamine, UDP-N-acetylglucosamine, UDP-xylose, CMP-sialic acid), recognizes one or at most a limited number of glycoconjugate acceptors and is competent to construct a single, specific glycosidic bond of either alpha or beta anomeric configuration. As it can be the case that two or more different glycosyltransferases can synthesize related or identical glycosidic bonds, and as there are hundreds of distinct glycan structures, it can be estimated that there are perhaps hundreds of different glycosyltransferases that are called upon to elaborate the molecules that comprise the glycocalyx (21).

Each glycosyltransferase is assigned membership in a general category of glycosyltransferases according to the sugar nucleotide it requires exclusively. For instance, enzymes that use GDP-fucose are termed fucosyltransferases, whereas those that use UDP-galactose are termed galactosyltransferases. Enzymes within such a subgroup may construct glycosidic bonds with an alpha anomeric configuration, whereas others may construct a beta anomeric linkage. The precise nature of 
the glycosidic linkage is indicated by numbers denoting the carbon atoms involved in the glycosidic bond that links the transferred monosaccharide to the acceptor. For example, an $\alpha 1$-3fucosyltransferase catalyzes the synthesis of an $\alpha$-anomeric linkage between carbon 1 of fucose and carbon 3 of an acceptor monosaccharide, whereas a $\beta 1$-4galactosyltransferase constructs a $\beta$-anomeric linkage between carbon 1 of galactose and carbon 4 of the acceptor.

Each glycosyltransferase is generally able to utilize only one specific glycan-based acceptor with high efficiency; as implied by the glycosyltransferase nomenclature, each enzyme typically adds the monosaccharide of its cognate sugar nucleotide substrate to a single specific hydroxyl group on the acceptor glycan, and virtually always constructs this specific glycosidic bond in only one of the two possible anomeric configurations. In some instances, specificity for a particular glycan is enhanced dramatically by a specific polypeptide that bears the glycan to which a monosaccharide is transferred, or by a specific class of glycan precursors that represents an optimal acceptor substrate. One of the best-characterized examples of peptide-specificity in glycosylation relates to a glycan modification and corresponding glycosyltransferase on pituitary glycoprotein hormones (23). In this instance, a $\beta 1$ $4 \mathrm{~N}$-acetylgalactosaminyltransferase acts efficiently on a glycan acceptor displayed by many proteins in the pituitary only

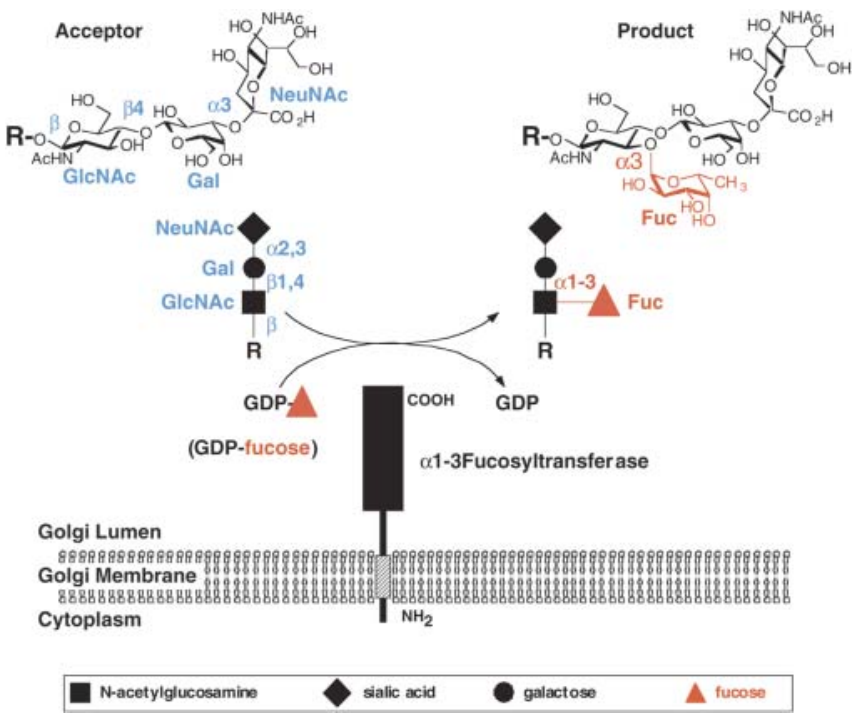

Fig. 1. Type II transmembrane topology and generic activity of a mammalian glycosyltransferase. In this example, the glycosyltransferase is an $\alpha 1-3$ fucosyltransferase. GDP-fucose is the sugar nucleotide substrate, and a trisaccharide is the acceptor substrate, displayed by an unspecific scaffold (R). The fucosyltransferase catalyze the formation of alpha anomeric glycosidic bond between carbon 1 of the fucose and carbon 3 of the GlcNAc in the trisaccharide acceptor. when that acceptor decorates the alpha subunit of luteinizing hormone. There are notable, if less well-studied, examples relevant to the selectin ligand field, however, including a glycan sulfotransferase relevant to HEV-borne L-selectin ligand. This enzyme exhibits remarkable specificity for O-glycans, relative to N-glycans (24). Similarly, FucT-IV and FucT-VII, a pair of fucosyltransferases involved in E- and P-selectin ligand biosynthesis (25), exhibit, respectively, apparent preferences for O-glycans borne by a P-selectin counter-receptor known as PSGL-1 and N-glycans that modify an E-selectin counterreceptor termed ESL-1 (26).

Glycosyltransferase-dependent synthesis of oligosaccharides generally involves an ordered assembly process, leading to both elongation and branching (Fig. $2 \mathrm{~A}$ and B). Typically, the glycan product of one glycosyltransferase is an acceptor substrate for one or more subsequent glycosyltransferases in the cell. If two (or more) glycosyltransferases can utilize an acceptor then, in principle, these enzymes can compete for this acceptor substrate, yielding two (or more) new products (Fig. 2C). Often, substantial amounts of such an acceptor substrate also may remain unmodified (Fig. 2C). Moreover, in some instances, a glycosyltransferase can form a product that is no longer an acceptor substrate for other enzymes in the cell (Fig. 2D). This formation can lead to termination of glycan chain modification, including termination of branching or elongation.

Layered on top of these straightforward principles for glycan synthesis are several additional factors that can function to modulate the relative steady level of accumulation of each of the potential glycan products in any given cell. One is these factors is, of course, the glycosyltransferase repertoire of any given cell type, and the corresponding repertoire of its glycan structures (few cell mammalian cell types, if any, have been completely characterized with respect to this pair of related biological entities). A second factor is the relative affinity of each enzyme in the repertoire for specific glycan acceptors which, as noted above, can be dictated by the chemical nature of the glycan portion of the acceptor, and by the nature of the polypeptide or lipid that displays this glycan component. A third factor is the relative abundance of each enzyme which, in turn, can be dictated by transcriptional and posttranscriptional control mechanisms (27). A fourth factor concerns possibilities for sub-Golgi compartmentalization of enzymes in vivo. Specifically, enzymes that are observed to compete for acceptors in vitro may in vivo occupy functionally distinct compartments within the secretory pathway, may be exposed to different subsets of identically terminated glycan acceptors, and thus may not compete for such acceptors in 


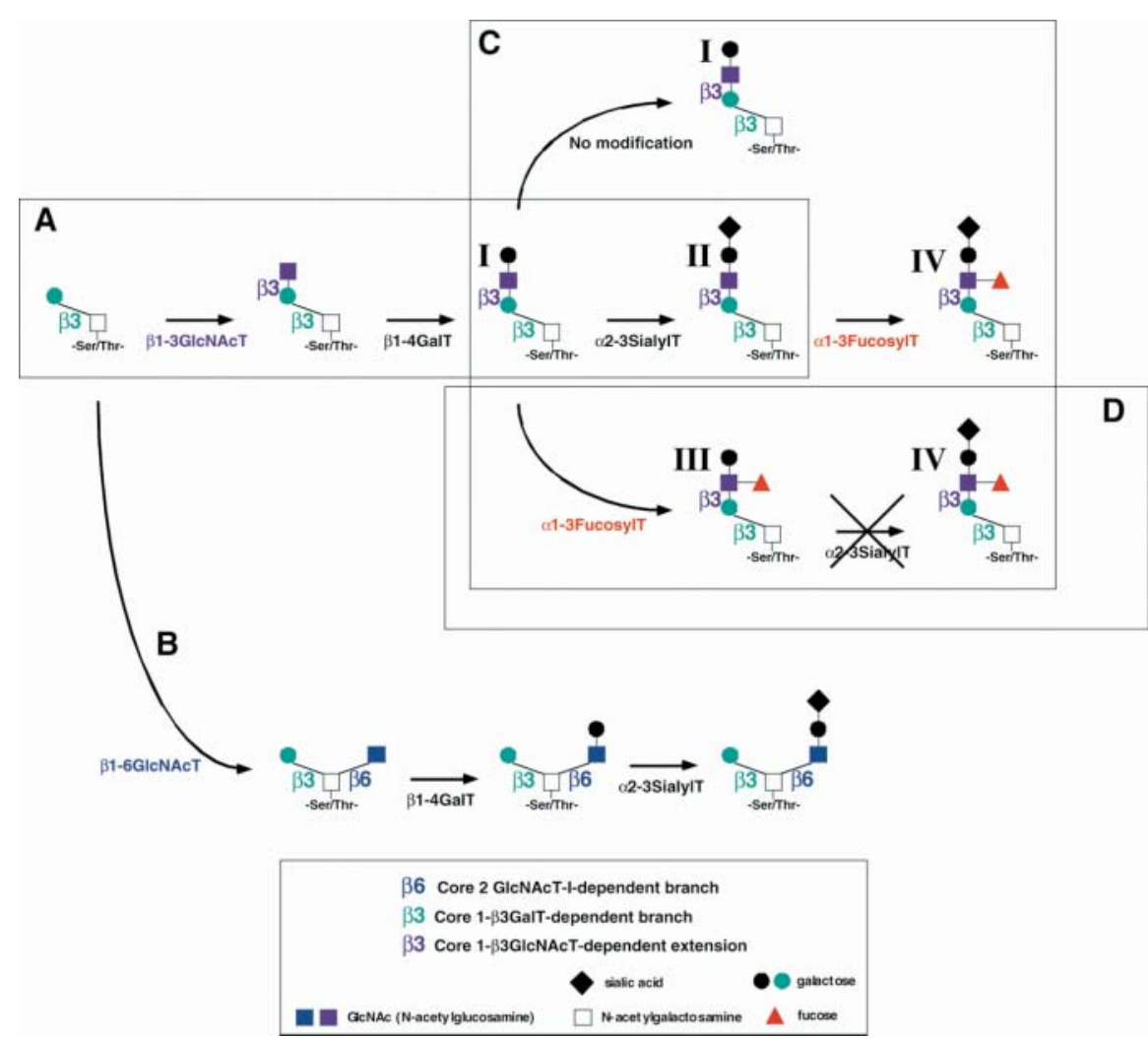

Fig. 2. Glycan elongation, branching and chain termination processes. Component monosaccharides are shown in the legend at the bottom of the figure. The $\beta 1-4-, \alpha 2-3-$ and $\alpha 1$-3-linkages implicit for galactose, sialic acid and fucose, respectively, are not shownexplicitly. The reader is referred to $[21,22]$ for specifics about cores 1 and 2 branching enzymes, the core 2 branching enzyme and the concepts illustrated here. The relevance of some of these pathways to selectin ligand synthesis is discussed in more detail later in this review. A) Glycan elongation. Glycan synthesis can proceed to generate a linear chain, initiating in this example with a core 1 O-glycan, and yielding a sialic acid-terminated glycan (structure II) (75). B) Glycan branching. Glycan synthesis can also yield branched chains, initiating in this example with a core 1 O-glycan that itself becomes elongated to form a sialic acid-terminated glycan. Combinations of $\mathbf{A}$ and $\mathbf{B}$ are possible, where both branches become linearly elongated (73-75). C) Competition among different glycosyltransferases for a common acceptor substrate. In this example, one acceptor substrate (structure I) can be used by a sialyltransferase and a fucosyltransferase to form different products (structures II and III, respectively) $(25,59)$. Some fraction of the acceptor may also remain unmodified within the secretory pathway. Thus, each of the structures I, II, and III may accumulate, and in relative proportions that are determined by processes discussed in the text. D) Glycan chain termination by the action of a glycosyltransferase. In this example $(25,59)$, a fucosyltransferase, acting on structure I, prevents further modification by sialylation to form structure IV because the sialyltransferase cannot use structure III. However, structure IV can be formed if structure II is formed first, and is then fucosylated (panel $\mathbf{C}$ ). the context of a living cell (28). A potential fifth factor concerns sugar nucleotide substrate availability (29).

Obviously, addition or deletion of a specific glycosyltransferase from such a synthetic system in vivo is likely to change the glycosylation phenotype of a cell. Addition of a glycosyltransferase gene may create new structures, and may simultaneously divert acceptor substrate away from preexisting pathways (i.e. addition of the $\beta 1-6 \mathrm{GlcNAcT}$ gene to a cell that does not normally express a $\beta 1-6 \mathrm{GlcNAcT}$ is likely to create the pathway in B of Fig. 2, and simultaneously diminish the products of the pathway in A). Conversely, deletion of a glycosyltransferase gene will certainly remove the corresponding glycosidic modification (assuming the cell's reper- toire of glycosyltransferases does not include an enzyme with identical capabilities). However, if the deleted enzyme is one of two or more that competes for an acceptor, compensatory increases in the "competing" pathways may ensue (i.e. deletion of the fucosyltransferase in Fig. $2 \mathrm{C}$ will eliminate structures III and IV, and may also increase synthesis of structures I and II). Unfortunately, the various factors discussed in the previous paragraph that may control competition for substrates are generally understood poorly, if at all, for most glycosyltransferases and cell types. It is thus difficult, at best, to make strong predictions about how the glycosylation phenotype of any given cell type will be perturbed, at least at the level of specific glycan structures on specific glycoconjugate 
platforms, in experiments where glycosyltransferases are added to or deleted from cells in a mammalian organism by transgenesis or targeted gene deletion. Consequently, there are corresponding difficulties in assigning a definitive molecular basis to account for phenotypes observed in such experimental systems. These are problems best solved, at this stage of the development of this field, by careful and comprehensive analysis of glycan structure in experimental contexts, where glycosylation phenotypes have been genetically perturbed. Some progress has been made in this area, as will be discussed below in the context of the selectin counter-receptors, and has yielded insights into many of the poorly understood factors that enter into glycosyltransferase-dependent control of glycan synthesis. Many more opportunities exist for developing structural correlates to manipulations of the glycosylation machinery, however, representing important tasks for the future.

\section{Lymphocyte homing and L-selectin counter-receptors on high endothelial venules}

Lymphocyte trafficking in mammals is characterized by the birth of lymphocyte progenitors in the bone marrow, their maturation in the marrow and thymus and circulation through the vascular tree. The itinerary of a circulating lymphocyte will eventually include the microvasculature of secondary lymphoid organs such as peripheral lymph nodes. While passing through the node, a fraction of the lymphocytes emigrate from the circulation to the parenchyma of the node; most return eventually to the vascular system by way of lymphatics, and will retrace their previous itineraries $(4,5)$. The term lymphocyte homing refers to the segment of this journey corresponding to trafficking from the circulation to lymph node parenchyma. The lymphocyte homing process applies to $\mathrm{T}$ and $\mathrm{B}$ lymphocytes, helps to maximize exposure of these cells to foreign antigens that are delivered to the node via other mechanisms and is an essential component of both cellular and humoral immunity.

Lymphocyte emigration to the parenchyma of peripheral nodes and other secondary lymphoid organs occurs in postcapillary venules lined by plump endothelial cells with specialized synthetic functions. These cells are termed high endothelial cells, or HEC. The corresponding venular structures are known as high endothelial venules or HEV. Functionally distinct HEV are found in different secondary lymphoid organs such as peripheral nodes and Peyer's patches, and in HEV that develop in inflamed organs. The idiosyncratic repertoire of adhesion molecules and chemokines made by each type of organ-specific HEV work in concert with the repertoire of adhesion molecules and chemokine receptors displayed by various lymphocyte subsets, to dictate the locale to which each such subset will emigrate (reviewed in (6) and (7)).

Initial insights into the molecular basis for lymphocyte homing to peripheral nodes were developed in part with the Stamper-Woodruff adhesion assay that assesses lymphocyte adhesion to frozen sections of peripheral nodes in vitro (30). Using this assay, a monoclonal antibody termed MEL-14 was found that blocks lymphocyte binding to peripheral node HEV (31). Subsequent studies demonstrated that MEL-14 can block lymphocyte homing in vivo, and assigned the MEL-14 epitope to L-selectin (reviewed in (3) and (4)). Creation and characterization of mice with targeted deletions of the L-selectin locus demonstrate a requirement for L-selectin in lymphocyte adhesion to peripheral node HEV and in lymphocyte homing $(32,33)$. It is now clear that lymphocyte homing, via peripheral node HEV, is characterized by low affinity, shear- and L-selectin-dependent lymphocyte rolling, chemokine-dependent lymphocyte activation and firm LFA-1-dependent adhesion $(5,14)$.

\section{Glycan-based L-selectin counter-receptors}

A glycoconjugate contribution to HEV-derived L-selectin counter-receptors was initially suspected in part because of the prominent glycocalyx on peripheral node HEV, and because in Stamper-Woodruff assays, exposed peripheral node HEV retain their ability to bind lymphocytes after glutaraldehyde fixation, which can destroy peptide epitopes but leaves glycan moieties intact (30). Additional indirect evidence for HEV-borne counter-receptors derived from observations in which specific monosaccharides and polysaccharides were found to inhibit lymphocyte adhesion to HEV $(34,35)$. Support for the involvement of sialylated glycans in lymphocyte adhesion was forthcoming from experiments showing that sialidase treatment of paraformaldehyde-fixed peripheral node HEV disabled lymphocyte adhesion (36). An in vivo correlate for these studies was developed by observing that lymphocyte homing to peripheral nodes in the mouse is specifically diminished following intravenous injection of Vibrio or Clostridial sialidases (37). Increasingly refined characterization of HEV-derived L-selectin counter-receptors used peripheral node organ culture to synthesize L-selectin counterreceptors, and deployed a chimeric protein comprised of the lectin, EGF and CR domains of mouse L-selectin fused to the hinge, $\mathrm{CH} 2$ and $\mathrm{CH} 3$ domains of a human IgG heavy chain to rescue and study such molecules (38). These studies (39- 
41) identified a molecule now termed GlyCAM-1 as a prominent HEV-derived counter-receptor for L-selectin. Counter-receptor activity associated with GlyCAM-1 is clearly sulfationdependent, as inferred by the prominent incorporation of radiolabeled sulfate into GlyCAM-1 in organ culture and as demonstrated by loss of binding when sulfation is blocked by chlorate $(39,40)$. Sialidase treatment destroyed the L-selectin ligand activity of GlyCAM-1, in correlation with the binding and lymphocyte homing studies discussed above. Absence of mannose labeling and resistance to $\mathrm{N}$-glycanase digestion indirectly excluded a role for $\mathrm{N}$-glycans in L-selectin ligand activity, whereas other observations inferred that GlyCAM-1 was modified by fucose-containing O-glycans $(39,40)$. Molecular cloning analyses have since demonstrated that GlyCAM-1 is a membrane-associated mucin-type glycoprotein (41), which accounts for the observation that GlyCAM-1 is secreted in lymph node organ cultures and is found as a circulating plasma protein (42). There is now strong experimental evidence that the vascular sialomucin CD34 also functions as an HEV-derived L-selectin counter-receptor (43). There is clearly redundancy in HEV-derived L-selectin ligands, because CD34 null mice maintain essentially normal L-selectin-dependent lymphocyte homing activity (44), as do GlyCAM-1 null mice (3). Notably, CD34 is widely expressed by vascular endothelial cells, but does not support L-selectin-dependent adhesion except when expressed in L-selectin ligand-positive HEV, because it is only in such cells that it acquires the posttranslational modifications required for L-selectin counter-receptor activity. HEV-derived L-selectin counter-receptor activity is also associated with MAdCAM-1 (45) and podocalyxin, another mucin-like protein (46), both of which are decorated with sialylated, sulfated O-glycans.

Possible structures for the sulfated, sialylated and fucosylated glycans associated with these L-selectin counter-receptors were suggested by the observation that L-selectin is able to can bind to sialyl Lewis $\mathrm{x}$, an oligosaccharide that contributes to both E- and P-selectin ligand activity $(47,48)$ (discussed detail below), and to sialyl Lewis $x$ and sialyl Lewis a, analogs where the terminal sialic acid moiety is substituted with a sulfate residue (49). These observations prompted the hypothesis that sulfated forms of the sialyl Lewis $\mathrm{x}$ tetrasaccharide modify O-glycans on GlyCAM-1, CD34, MAdCAM-1, and podocalyxin, and endow them with L-selectin counter-receptor activity. This hypothesis is now supported strongly by examinations of the structures of the glycans associated with GlyCAM-1 (50-53), anti-HEV monoclonal antibody reagents (54), modulation of glycosylation phenotypes by transfection of glycosyltransferase genes into cultured cell lines (55-57) and analysis of glycosyltransferase and sulfotransferase mutant mice $(25,58-61)$.

\section{Sulfation, sulfotransferases and L-selectin counter- receptors}

Analyses of the glycans associated with GlyCAM-1 derived from mouse peripheral nodes identified three sulfated forms of the sialyl Lewis $\mathrm{x}$ moiety as candidate "capping" groups on L-selectin counter-receptors (50-54). These are 6'sulfosialyl Lewis x, 6'sulfosialyl Lewis $x$ and 6',6 bisulfosialyl Lewis $x$ (Fig. 3). Substantial amounts of the monosulfated sialyl Lewis $x$ components were observed to be part of a core-2 type Olinked glycan. These studies also provided evidence that GlyCAM-1 might bear longer polymeric forms of these structures with potential for multiple sites of $\alpha 1-3$ fucosylation (53).

Biochemical and genetic evidence infer that in the synthesis of such sulfated glycan moieties, sulfation, catalyzed by one or more glycan O-sulfotransferases that utilize the high energy sulfate donor PAPS (phosphoadenosine phosphosulfate), would precede $\alpha 2$-3sialylation, which would in turn be followed by $\alpha 1$-3fucosylation $(4,25)$. At the time that the capping groups had been proposed, however, the identities of the sulfotransferases involved in their construction were not clear. Previous molecular cloning studies had identified a sulfotransferase responsible for 6-O galactose sulfation in keratin sulfate biosynthesis (62) and a structurally related 6-O GalNAc sulfotransferase involved in chondroitin sulfate biosynthesis (63). In vitro, but with low efficiencies, both enzymes can add sulfate in the 6 position to the galactose moiety on $\alpha 2$-3 sialyl-N-acetyllactoseamine, a precursor to the $6^{\prime}-\mathrm{O}$ sulfated sialyl Lewis $x$ structures $(62,63)$. These observations and distant primary sequence similarities between segments of the catalytic domains of a number of cloned sulfotransferases suggested the possibility of using these sequences to probe sequence databases for new candidate 6-O sulfotransferases that contribute to L-selectin counter-receptor glycan sulfation. Database searches performed independently by two groups yielded cDNAs encoding several sulfotransferases. One of these enzymes, termed LSST by one group (56) and HECGlcNAc6ST by another (57), corresponds to a protein with a predicted type 2 transmembrane topology typical for glycosyltransferases and previously cloned glycan sulfotransferases. These enzymes, now termed GST-3, and the other sulfotransferases, are members of a growing set of family of galactose/ $\mathrm{N}$-acetylgalactosamine/N-acetylglucosamine 6-O-sulfotransferases (GSTs). The nomenclature and substrate specificities of these enzymes have been reviewed elsewhere $(61,64)$. 
A

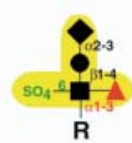

6-sulfosialyl Lewis $\mathrm{x}$

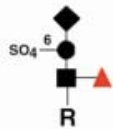

6'-sulfosialyl Lewis $x$

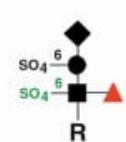

6', 6-bisulfosialyl Lewis $\mathrm{x}$

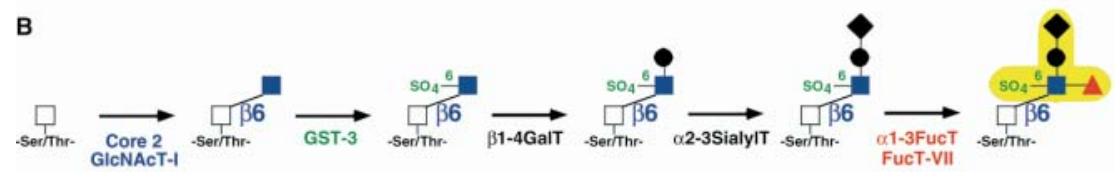

Core 2-type 6-sulfosialyI Lewis $x$

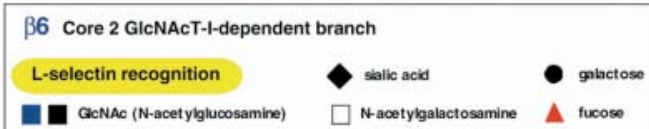

Fig. 3. "Capping” groups L-selectin counterreceptors, and synthesis of core 2-type 6sulfosialyl Lewis x. Component

monosaccharides are shown in the legend at the bottom of the figure. The $\beta 1-4-$,

$\alpha 2-3$-, and $\alpha 1$-3-linkages for galactose, sialic acid and fucose, respectively, are shown explicitly on the 6-sulfosialyl Lewis $\mathrm{x}$ structure in panel A only, but are implicit to all other structures in the figure. A) Capping groups. Initial evidence for the existence of these structures is provided in $(50,51)$. Yellow shading on the 6-sulfosialyl Lewis $x$ structure indicates that this moiety can confer L-selectin ligand activity upon core 2-type and/or extended core 1-type O-glycans (R) (see panel B below, and Fig. 4 for structural details). The 6'-sulfosialyl Lewis $x$ and 6', 6-sulfosialyl Lewis $\mathrm{x}$ structures are not shaded because evidence that either of these two isomers can confer L-selectin ligand activity is less compelling. B) Order of synthesis of core 2type 6-sulfosialyl Lewis $\mathrm{x}$.

Monosaccharidesand corresponding enzymes with lineage restricted specific expression patterns that include HEVs are colorized. Monosaccharides and corresponding enzymes with widespread expression patterns are shown in black. Core 2 GlcNAcT-I creates a core $2 \beta 1-6$ branch by modifying GalNAc moieties on serines or threonine residues in GlyCAM1, CD34 and other mucin-type glycoproteins. The resulting GlcNAc moiety is a substrate for GST-3. The 6-O-sulfated GlcNAc residue is then a substrate for $\beta 1-4 \mathrm{GalT}(\mathrm{s})$, whose product is in turn a substrate for $\alpha 2$ 3 sialylT(s). The $\alpha 1$-3fucosyltransferase FucTVII then acts on this sialylated, 6-O-sulfated core 2 O-glycan to form 6-sulfosialyl Lewis x, which is active as an L-selectin ligand. Evidence to support this order of synthesis is provided and/or discussed in $(25,53,55-$ $57,59,61,64)$ and $(75)$.
The properties of GST-3, known formerly as LSST or HECGlcNAc6ST, assign it a prominent role in L-selectin ligand carbohydrate sulfation $(55,56,65)$. First, GST-3 transcripts localize primarily to high endothelial cells in peripheral lymph nodes, and they are also induced in L-selectin counterreceptor-positive HEVs that develop in concert with lymphoma in the thymus of AKR/J mice (56). In cultured cells transfected with the CD34, a core 2 GlcNAc-transferase (core 2 GlcNAcT) and an $\alpha 1$-3fucosyltransferase (FucT-VII), transfection with GST-3 clearly confers L-selectin ligand activity upon the cells, whether assayed by flow cytometry using an L-selectin-IgM chimera or in L-selectin- and shear-dependent cell adhesion assays in vitro, using a flow chamber $(55,56)$.
In vitro, this enzyme catalyzes the transfer of sulfate from PAPS to the 6 hydroxyl of the GlcNAc moiety on core 2-type Oglycans that are precursors to the sialyl Lewis $\mathrm{x}$ tetrasaccharide. Structural analyses of the sulfation characteristics of this enzyme in transfected cell lines demonstrate that GST-3 maintains a remarkable preference for core 2-type O-linked glycans, where it catalyzes 6-O sulfation of GlcNAc on core 2 O-glycans, but does not sulfate N-linked glycans (56). These observations indicate that GST-3 can account for the synthesis of at least some of the 6-sulfosialyl Lewis $x$ determinants that modify GlyCAM-1, CD34 and MAdCAM-1 $(55,56,65)$.

An in vivo role for this enzyme in L-selectin ligand activity on HEV has been explored by constructing and analyzing 
mice with an induced null mutation in the GST-3 locus (60). In these mice, deletion of GST-3 is associated with a significant reduction in L-selectin ligand activity on peripheral node HEV. This reduction is characterized by loss of binding of an L-selectin Ig chimera to the lumenal face of the HEV, but apparent retention of binding to the ablumenal side of the venules. Loss of lumenal binding is associated with significant reductions in short-term trafficking of transfused wild-type lymphocytes to the peripheral nodes, and a decrease in the number of endogenous lymphocytes in the peripheral nodes. In contrast to the changes observed in the peripheral nodes, little if any alteration was observed in mesenteric nodes and Peyer's patches, where L-selectin-dependent lymphocyte homing plays a less prominent role (66) and where GST-3 would not be expected to contribute to lymphocyte homing. These observations assign GST-3 to a major role in the synthesis of L-selectin counter-receptor activity in peripheral node HEV, and they indicate that this enzyme accounts for a key glycan sulfate modification (6-sulfosialyl Lewis $\mathrm{x}$ ) on the O-glycans that decorate CD34 and GlyCAM-1, and perhaps MAdCAM-1 and podocalyxin.

GST-3-null mice retain significant amounts of L-selectin ligand activity, at least as defined by short-term in vivo lymphocyte homing assays. This observation indicates that peripheral node HEV can elaborate GST-3-independent L-selectin counter-receptor activities. The structure(s) of the glycans that may contribute to these residual activities have not yet been determined, and it is not known if such residual activities are sulfation-dependent. Other sulfotransferases, which have been evaluated with respect to a contribution to sulfation events relevant to L-selectin counter-receptor activity, include two widely expressed Gal-6-sulfotransferases (chondroitin sulfate 6-sulfotransferase, or GST-0 (67), and keratan sulfate Gal-6-sulfotransferase, or GST-1(68)), and a GlcNAc-6-sulfotransferase (GlcNAc6ST, or GST-2 (69)). However, none of these enzymes apparently exhibit specificity for core 2-type O-glycan acceptors (66). GST-1 is capable of generating Lselectin counter-receptor activity when expressed in cultured cells stably transfected with core 2-GlcNAc-transferase, FucTVII and CD34 (55). This enzyme is inconsistently able to synergize with GST-3 in the formation of L-selectin ligands $(55,65)$, however, and synergism between any pair of sulfotransferases has not yet been observed consistently (65). GST-2 is expressed in HEV and elsewhere and can construct the 6-sulfosialyl Lewis x moiety in transfected endothelial cells (57). A consensus on the ability of GST-2 to contribute to Fuc-TVII-dependent L-selectin ligand activity in transfected cells is not yet available $(56,57)$, nor is it clear if it contributes to selectin ligand activity in HEVs in vivo. GST-4 is a GlcNAc-6sulfotransferase whose expression is restricted to the intestine (67). Its ability to participate in the construction of L-selectin counter-receptor activity in cultured cell lines or in vivo is unknown. GST-5, a novel GalNAc 6-O-sulfotransferasetermed chondroitin 6-sulfotransferase-2 (71), is able to construct 6O-sulfated GlcNAc on the O-glycans in transfected cells (68). It remains to be determined if this enzyme can also create Lselectin ligands in transfected cells or if it contributes to Lselectin counter-receptor activity in vivo.

Considered together, the available data document a requirement for a specific 6-O-galactose sulfation in L-selectin counter-receptor activity, identify GST-3 as a prominent contributor to this sulfation event in vivo and infer that 6-sulfosialyl Lewis x capping groups contribute prominently to L-selectin counter-receptor activity. The sulfotransferases GST-1 and GST-2 have each been observed to construct L-selectin counter-receptor activity when coexpressed with CD34 and/ or GlyCAM-1, and with FucT-VII, in cultured cells, but their roles in this process in vivo remain to be established.

\section{Core 2 GlcNAc transferases, extended core I structures, L-selectin counter-receptor activity and the MECA-79 epitope}

The glycan structural analyses that identified 6- and 6'sulfosialyl Lewis x capping groups on GlyCAM-1 $(60,61)$ also suggested that core 2-type O-glycans may display such capping groups. Core 2-type O-glycans are the product of $\beta 1$ 6GlcNAc-transferases, referred to generically as core $2 \mathrm{GlcNAc}$ transferases. At least three distinct core 2 GlcNAc transferase loci have been discovered, corresponding to enzymes now termed core 2 GlcNAcT-I, -II and -III $(73,74)$. The in vivo functional relevance of core $2 \mathrm{O}$-glycans in L-selectin counterreceptor activity has been assessed through the creation and analysis of mice with a targeted deletion in the core 2 GlcNAcT-I locus (58). A slight reduction in the amount and/ or affinity of L-selectin counter-receptors was observed on the peripheral node HEV of these animals, as assessed by immunohistochemistry and an L-selectin IgM chimera. However, lymphocyte homing was found to be essentially normal in these mice, as assessed by short-term in vivo lymphocyte homing assays, and as inferred by the nearly normal number of endogenous lymphocytes in peripheral nodes, mesenteric nodes, and Peyer's patches.

Normal L-selectin ligand activity in the face of core 2 GlcNAcT-I deficiency was hypothesized to be consequent to expression of other core 2 GlcNAc transferases in the periph- 
GlyCAM-1-associated glycans

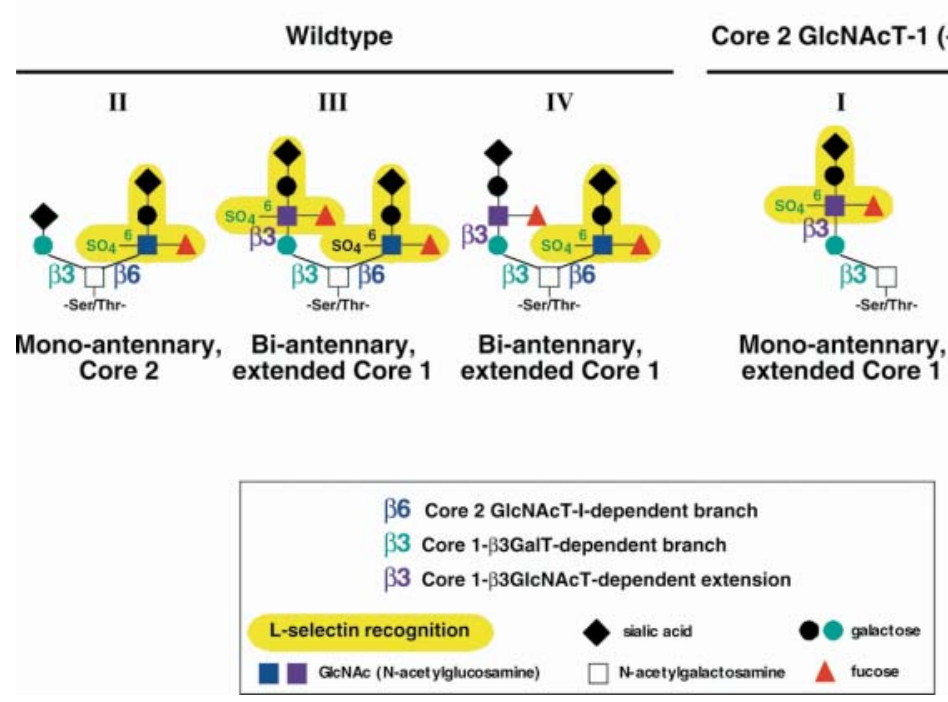

Fig. 4. Core 2 and extended core 1 structures associated L-selectin counter-receptors, and the MECA-79 epitope in mice.

Component monosaccharides are shown in the legend at the bottom of the figure. Monosaccharides and linkages catalyzed by the core 1- $\beta 3$ GlcNAcT extension enzyme, core 2 GlcNAcT-I branching enzyme and core 1$\beta 3 \mathrm{GalT}$ branching enzyme are shown in magenta, dark blue and turquoise, respectively. The 6-sulfosialyl Lewis x moiety required for L-selectin counter-receptor activity is shaded in yellow. The minimal chemical structure for the MECA-79 epitope is shown at right, and exists in structures I and III. The figure shows representative structures associated with GlyCAM-1 purified from the peripheral node HEVs of either wild-type mice, or core 2 GlcNAcT-I (-/-) mice. As discussed in the text, these structures have also been reconstituted using $\mathrm{CHO}$ cells expressing cDNAs encoding GlyCAM-1, FucT-VII, and GST3 , and expressing endogenous polypeptide GalNAcT(s), core $1-\beta 3 \mathrm{GalT}(\mathrm{s})$, and $\alpha 2$ -

3 sialylT(s). Using these cells, transfection with a core 1- $\beta 3$ GlcNAcT cDNA yields core 2deficient glycans with a core 1 extension of the type found in core 1- $\beta 3$ GlcNAcT $(-/-)$ mice (structure I). When such cells are transfected instead with core 2 GlcNAcT-I, only core 2-type glycans are made (structure II) Co-expression of core $1-\beta 3 \mathrm{GlcNAcT}$ and core 2 GlcNAcT-I also yields bi-antennary molecules (structures III and IV). eral node HEV that might compensate for the loss of core 2 GlcNAcT-I, or to L-selectin counter-receptor activities that were independent of core 2 branching. Analysis of the glycans elaborated by the HEV in core 2 GlcNAcT-I null mice have shown recently that the latter possibility is the correct one (75). Specifically, this work discloses an absence of core 2type O-glycans among sulfated, sialylated O-glycans purified from the core 2 GlcNAcT-I null HEVs in organ culture (Fig. 4). These observations exclude the need to invoke a compensatory role for other Core 2 GlcNAcT activities in maintaining essentially normal L-selectin counter-receptor activities in the core 2 GlcNAcT-I null mice. However, these glycan structural analyses identified a set of novel glycans based on an extended core 1-type O-linked glycan associated with HEV-derived mucin-type glycoproteins with 6-sulfosialyl Lewisx capping groups (Fig. 4).

Synthesis of extended core 1-type O-linked glycans depends on a corresponding core 1- $\beta 3$ GlcNAcT, although such enzymes had not been cloned or characterized. However, previous studies had found moderate primary sequence similarities be- tween three $\beta 1$-3-galactosyltransferases and a $\beta 3$ GlcNAc-T whose catalytic properties were somewhat similar to the core $1-\beta 3$ GlcNAcT activity necessary to construct the core 1-type extension (76). Conserved segments of these four loci were thus used to screen sequence database in an effort to identify candidate core $1-\beta 3 \mathrm{GlcNAcT}$ loci (75). These screens identified a human locus whose corresponding transcripts localize to HEV and whose sequence predicted a type II transmembrane topology. The catalytic activity of the protein was explored by expressing a soluble fusion protein containing the predicted catalytic domain. In vitro, this fusion protein was found to utilize UDP-GlcNAc, transferring GlcNAc to a synthetic core 1 glycan analog (Gal $\beta 1-3 \mathrm{GalNAc} \alpha 1-\mathrm{R})$ to form a core 1 extension (GlcNAc $\beta 1-3$ Gal $\beta 1-3$ GalNAc $\alpha 1-R)$. The fusion protein could also add GlcNAc to a low molecular weight core 2 acceptor substrate $[\mathrm{Gal} \beta 1-3($ GlcNAc $\beta 1-6)$ GalNAc $\alpha 1-\mathrm{R}]$ to form a core 1 extension on a core 2-type glycan [9GlcNAc $\beta 1$-3Gal $\beta 1-$ 3 (GlcNAc $\beta 1-6)$ GalNAc $\alpha 1-R]$.

To assess the functional relevance of this core 1 extension as a carrier for 6-sulfosialyl Lewis $\mathrm{x}$ determinants and as a 
contributor to L-selectin counter-receptor activity, Chinese hamster ovary cells were first reconstituted with GlyCAM-1 or CD34 plus GST-3 plus the $\alpha 1$-3fucosyltransferase FucT-VII. These cells were then transfected with a core 1- $\beta 3$ GlcNAcT cDNA, with a core 2 GlcNAcT-I cDNA, or with both cDNAs, the structures of the mucin-associated glycans were defined, and the ability of the cells to support L-selectin-dependent lymphocyte tethering under shear was examined. These studies disclosed that ore 2 GlcNAcT-I expression or core 1$33 \mathrm{GlcNAcT}$ expression enhances L-selectin counter-receptor activity expressed by the $\mathrm{CHO}$ cell transfectants, as assessed by lymphocyte rolling under shear. These studies thus supported the hypothesis that deletion of core 2 GlcNAcT-I leaves extended core 1 structures capable of supporting essentially normal lymphocyte homing in the core 2 GlcNAcT-I null mice. Co-expression of core 2 GlcNAcT-I plus core 1B3GlcNAcT yielded CHO cells whose ability to capture lymphocytes under shear was additive and possibly synergistic, relative to the cells expressing one of the enzymes only.

To develop a molecular correlate for the transfection and core 2 GlcNAcT-I deletion experiments, glycan structural analyses were completed on GlyCAM-1 rescued from the transfected CHO cells. These studies identified core 2-type 6sulfosialyl Lewis $\mathrm{x}$ structures as a primary structure in core 2 GlcNAcT-I transfectants, and extended core 1-type O-glycans bearing 6-sulfosialyl Lewis x structures in core 1- $33 \mathrm{GlcNAcT}$ transfectants (Fig.4). Bi-antennary O-glycans containing 6sulfosialyl Lewis $\mathrm{x}$ on both the core 1 extension and on the core 2 branch were observed in the double transfectants (Fig. 4). In wild-type mice, GlyCAM-1 was shown to express a similar range of structures, including bi-antennary O-glycans where each branch contained a 6-sulfosialyl Lewis x moiety.

Considered together, these studies suggest that core 2 GlcNAcT-I and core 1-B3GlcNAcT can cooperate to yield the most potent L-selectin counter-receptors, and afford peripheral node HEV with redundancy in glycan synthesis. Confirmation of these notions will be assisted by the creation and analysis of mice in which extended core 1 structures have been deleted by targeted inactivation of the core $1-\beta 3$ GlcNAcT locus in the mouse.

These studies also uncovered the chemical structure of the glycan epitope recognized by the MECA-79 monoclonal antibody (75). This antibody had been used for many years as a marker of HEVs, had been associated with L-selectin ligand activities since it can inhibit binding of lymphocytes to HEV in vitro and in vivo (38) and had been used to isolate L-selectin ligands biochemically (38-40). More recent work has shown that sialic acid and fucose do not contribute to
MECA-79 reactivity (75), although the precise structure(s) recognized by the antibody had been mysterious. By reconstituting MECA-79 reactivity in cultured cell lines and with the aid of a panel of synthetic glycans, it was demonstrated that the MECA-79 epitope corresponds to the 6-sulfated, extended core 1 glycan Gal $\beta 1-4[6$-sulfo]GlcNAc $\beta 1$-3Gal $\beta 1$ 3GalNAco1.

\section{$\alpha \mathrm{I}-3$ Fucosylation and L-selectin counter-receptor activity}

A contribution by $\alpha 1-3$ fucosylation to L-selectin counter-receptor activity was implied by the requirement for this modification for E- and P-selectin counter-receptors $(2,3)$, by strong primary sequence similarities shared by the E-, P- and L-selectin CRDs, and by the observation that the sialyl Lewis $x$ moiety could support L-selectin binding under some experimental conditions in vitro $(47,48)$. Direct evidence that $\alpha 1-$ 3fucosylation is required for L-selectin counter-receptor activity in vivo derives in part from analysis of mice with a targeted deletion of the FucT-VII locus (59), which encodes an $\alpha 1$ 3 fucosyltransferase expressed in HEV (77). There is an 8090\% reduction in short-term lymphocyte homing in FucTVII null mice, a corresponding reduction in the number of lymphocytes that can be recovered from their peripheral nodes $(59,78)$, and their peripheral node HEV do not bind an L-selectin-IgM chimera (59). When considered with in vitro studies showing that FucT-VII can utilize 6-O-sulfated $\alpha 2$ 3 sialylated lactosamine precursors to form the 6-sulfosialyl Lewis $\mathrm{x}$ moiety, these observations suggest that the L-selectin counter-receptors in these mice are relatively or perhaps absolutely deficient in the 6-sulfosialyl Lewis x tetrasaccharide. FucT-VII can also contribute to L-selectin counter-receptor activity in cultured cells cotransfected with cDNAs encoding FucT-VII, protein "scaffolds" such as CD34 and GlyCAM-1, sulfotransferase cDNAs that have included GST-3 and core 2 GlcNAcT-I, using cells that express endogenous $\alpha 2$-3sialyltransferase activities $(55-57,65,75)$. Considered with the observations made in FucT-VII null mice, these studies have inferred that FucT-VII is a primary participant in controlling L-selectin counter-receptor activity and 6-sulfosialyl Lewis x synthesis.

Residual lymphocyte homing is retained in the FucT-VII null mice, however, and the peripheral nodes are not reduced in size, as has been observed in L-selectin null mice $(32,33)$. These observations implied the existence of fucosylation-independent L-selectin counter-receptor activities, or that one or more other $\alpha 1-3$ fucosyltransferases accounted for the re- 
sidual homing. The latter possibility has been confirmed by creating and analyzing mice with combined deficiency of FucT-VII and a second $\alpha 1-3$ fucosyltransferased termed FucTIV (25). FucT-IV(-/-)/FucT-VII(-/-) doubly deficient mice have extremely small peripheral lymph nodes reminiscent of those reported in L-selectin null mice (25). Residual lymphocyte homing observed consistently in the FucT-VII null mice is absent in the doubly deficient mice (25), with a correspondingly extreme paucity of lymphocytes in their peripheral nodes. The peripheral nodes are in fact virtually devoid of naïve $\mathrm{T}$ lymphocytes, whose homing to peripheral lymph nodes requires L-selectin (79). The FucT-IV null mice are, by contrast, without detectable defects in either lymphocyte homing or peripheral node phenotypes, indicating clearly that FucT-VII-dependent synthetic events in the assembly of L-selectin counter-receptors supercede FucT-IV-dependent contributions.

A direct assignment of these phenotypes to differences in GlyCAM-1-mediated, shear-dependent lymphocyte adhesion has been developed using flow chamber-based in vitro adhesion assays (25). As noted above, GlyCAM-1 is released into the circulation from the HEV, and can be purified from the serum of mice (80). Wild-type GlyCAM-1 and GlyCAM-1 purified from the sera of mice with deficiencies in FucT-IV, FucT-VII or both was used to coat the bottom surface of a parallel plate flow chamber. Wild-type mouse lymphocytes were then passed through the chamber and allowed to interact with this L-selectin counter-receptor coated surface under physiologically relevant shear forces. Lymphocyte tethering events mediated by the wild-type or mutant-derived GlyCAM-1 s were captured by videomicroscopy and quantitated. These experiments disclose identical tethering efficiencies mediated by wild-type and FucT-IV-derived GlyCAM-1. By contrast, there is a substantial decrease in tethering activity when FucT-VII null-derived GlyCAM-1 is used to tether lymphocytes under shear, and there is no detectable tethering when using GlyCAM-1 purified from the serum of the FucT-IV/FucT-VII doubly deficient mice (25). These observations provide strong evidence that the phenotypes observed in the FucT null mice are accounted for by alterations in the glycan structures that decorate GlyCAM-1 and other HEV-borne L-selectin counter-receptors in these mice. These observations also confirm that functionally relevant fucosylation of L-selectin counter-receptors is dominated by FucT-VII, as a role for FucT-IV in this process is apparent only in the absence of FucT-VII.

Catalytic correlates for these observations have been developed using low molecular weight precursors for some of the molecules in Fig. $3(25,59)$. These data indicate that FucTVII can utilize, and may in fact require, precursors that are $\alpha 2-3$ sialylated. This enzyme is thus predicted to form either the sialyl Lewis x moiety, or the 6-sulfosialyl Lewis x structure, depending on whether the precursor is also 6-O-sulfated. These studies also indicate that the 6'-O-sulfated, $\alpha 2$-3sialylated precursor to $6^{\prime}$-sulfosialyl Lewis $\mathrm{x}$ is not a substrate for FucT-VII $(25,59)$. These observations imply that sialylation and sulfation precede fucosylation in the formation of 6-sulfosialyl Lewisx, and infer that 6'sulfation, if it occurs, must do so after FucT-VII-dependent fucosylation. By contrast, these data indicate that FucT-IV may utilize non-sialylated, 6O-sulfated precursors more effectively than the $\alpha 2$-3sialylated glycans much preferred by FucT-VII, and thus may contribute to the synthesis of non-sialylated isomers of these molecules that may also support L-selectin-dependent adhesion (81). It is not yet known if such non-sialylated 6-O-sulfated, $\alpha 1$ 3fucosylated molecules are elaborated by HEVs, if they contribute to L-selectin counter-receptor activity and lymphocyte homing, or whether they could be increased in the absence of FucT-VII (25). Characterization of the structures of the GlyCAM-1-associated glycans taken from the fucosyltransferase null strains will be required to address these uncertainties.

\section{E- and P-selectin counter-receptors on blood leukocytes}

Often, as alluded to above, progress made on E- and P-selectin counter-receptor structure and function has informed us about the biology and biochemistry of L-selectin counter-receptors. The glycan structural paradigms discussed above for L-selectin counter-receptors on HEV are thus in many ways reflective of those that apply to leukocyte counter-receptors for E- and P-selectin. None the less, the depth of understanding concerning leukocyte selectin counter-receptors may currently lag that developed for L-selectin ligands. This is due in part to the fact that HEV organ culture and radiochemical labeling techniques used to discover glycan structures relevant to L-selectin counter-receptors cannot be used as effectively with blood neutrophils, whose glycan synthetic program is considered to be nearly quiescent and whose cell surface glycan repertoire is likely to be matured at progenitor stages in the marrow. However, a considerable amount is known about leukocyte selectin counter-receptor structure developed, in part, through analysis of cultured leukocyte cell lines.

As reviewed elsewhere $(2,3)$, early studies associated E-selectin ligand activity with the sialyl Lewis $\mathrm{x}$ tetrasaccharide, although the nature of the molecules that displayed this gly- 
can were not defined, nor was it clear that such molecules contributed to counter-receptor activity. It is now known that glycolipids can display E-selectin counter-receptor activity, in vitro at least (82), and that the structure of such molecules includes the sialyl Lewis $\mathrm{x}$ determinant and/or its internally fucosylated isomer VIM-2. It remains to be determined if or how glycolipids contribute to E-selectin counter-receptor activity in a bona fide leukocyte in vivo. E-selectin counter-receptor activity has also been associated with specific glycoproteins on neutrophils, monocytes, some types of $\mathrm{T}$ and $\mathrm{B}$ lymphocytes and eosinophils (reviewed in (2) and (3)). These molecules include L-selectin (in humans, but not in the mouse) $(83,84)$, ESL- 1 , a variant of a molecule also identified as an FGF receptor (85) and a mucin-type glycoprotein known as P-selectin glycoprotein ligand-1 (PSGL-1) (reviewed in (2) and (3)). Evidence that PSGL-1 makes a physiological contribution to E-selectin ligand activity has been developed largely through the creation and analysis of mice with targeted deletions of the PSGL-1 locus $(86,87)$; the neutrophils in these animals exhibit subtle defects in E-selectin counter-receptor activities. For each of these E-selectin counter-receptors, there is direct, indirect or inferred evidence that counter-receptor activity is conferred upon them by $\mathrm{N}$ - and/or O-glycans containing the sialyl Lewis $\mathrm{x}$ tetrasaccharide and/or its isomers.

P-selectin counter-receptor activity has also localized to specific cell surface glycoproteins, including CD24 (2), but there is general consensus that leukocyte P-selectin counter-receptor activity can be ascribed primarily to PSGL-1 (reviewed in $(2,3,86,87))$. Initial clues to the importance of this molecule as a P-selectin ligand came from two distinct directions. In one instance, purification of P-selectin counter-receptors from a human leukocyte cell line identified this protein and no other (88). In another instance, a strategy designed to clone cDNAs encoding P-selectin counter-receptors rescued a cDNA encoding PSGL-1 (89). This work and related studies indicate that reconstitution of P-selectin counter-receptor activity in cultured cell lines requires PSGL-1 together with $\alpha 2$ 3 sialylation, $\alpha 1$-3fucosylation, core 2 GlcNAcT and protein tyrosine sulfation (89-92). Sulfation of one or more of the few tyrosines near the NH2-terminus clearly imparts an important contribution to P-selectin counter-receptor activity of PSGL-1 (89-92). A structural basis for many of these observations has been developed through X-ray crystallographic analysis of selectin CRD-ligand complexes (93). Insight into the relevance of the sulfate modification to P-selectin ligand activity in vivo is anticipated, now that the relevant sulfotransferases have been cloned (94) and tyrosine sulfotransferase null mice have been constructed (95).

\section{PSGL-I-associated O-glycans}

The nature of glycan modifications relevant to PSGL-1-associated P- and E-selectin counter-receptor activities has been forthcoming in part from a detailed characterization of the O-glycans that decorate PSGL-1 in the human promyelocytic leukemia cell line known as HL-60 (96). These analyses identify two types of core 2-type O glycans containing the sialyl Lewis $x$ determinant (Fig. 5). These include a core 2 type O-glycan with a single, typical sialyl Lewis $\mathrm{x}$ capping group, and core $2 \mathrm{O}-$ glycan extended by polylactosamine on the core 2 branch, modified by three fucosylation sites, and capped with a sialyl Lewis x moiety.
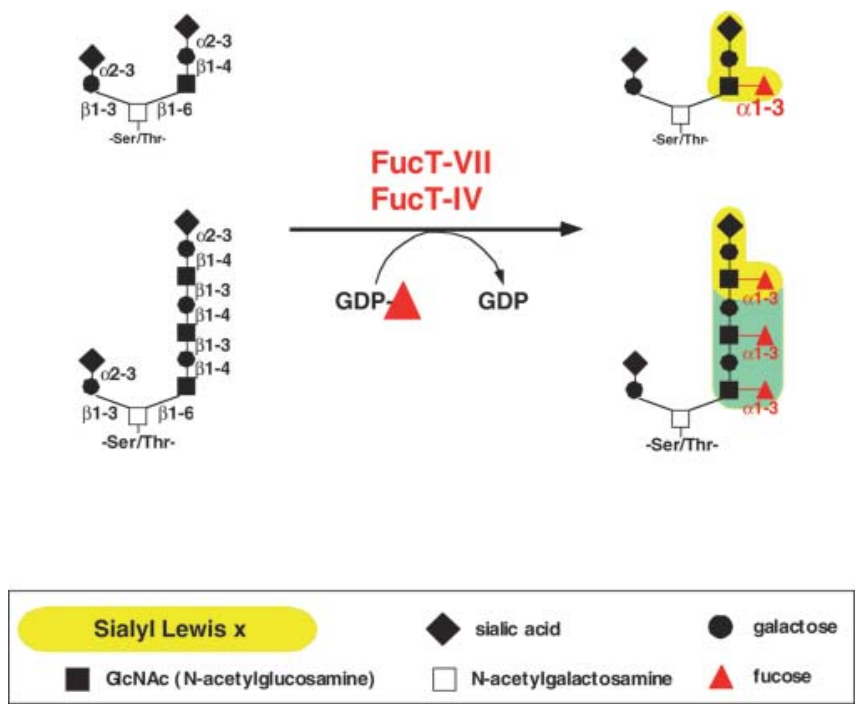

Fig. 5. Core 2-type, sialyl Lewis $\mathrm{x}$-containing O glycans on HL60 cell-derived PSGL-1. Component monosaccharides are shown in the legend at the bottom of the figure. The $\beta 1-4-, \alpha 2-3$ - and $\beta 1$ 3-linkages for galactose, sialic acid and $\mathrm{N}$-acetylglucosamine, respectively, are shown explicitly in the structures at left, but are implicit to the structures on the right. The two types core 2-type Oglycans found on HL60 cell PSGL-1 that contain the sialyl Lewis $x$ moiety (shaded in yellow) are shown at right (96). The triply a1-3fucosylated core 2-type glycans on an extended polylactosamine structure, and the mono $\alpha 1$-3fucosylated core 2 isomer can be formed in vitro and in vivo by the action of the $\alpha 1$ 3 fucosyltransferases FucT-IV and/or FucT-VII on the non-fucosylated precursors shown at left [reviewed in $(2,3,25,90,97)]$. The singly fucosylated glycan can support P-selectin ligand activity when it modified a tyrosine sulfated peptide derived from the amino terminus of PSGL-1 (97). Experiments to determine if the subterminal fucose moieties (shaded in green) and/or the extended configuration of the triply fucosylated isomer will contribute to P-selectin ligand activity in this context (97) have yet to be published. However, X-ray crystallography studies imply that the CRDs of E- and P-selectins will not require more than the sialyl Lewis $\mathrm{x}$ tetrasaccharide for high-affinity interaction (93). 
To determine how these two structures may contribute to P-selectin counter-receptor activity, chemoenzymatic syntheses were used to generate and evaluate tyrosine sulfated peptides derived from the amino terminal segment of PSGL1 and modified with variants of the monofucosylated core 2type sialyl Lewisx moiety (97). These studies show that a tyrosine sulfated peptide modified with the monofucosylated core 2-type O-glycan maintains an affinity for P-selectin that is equal to the affinity observed with native, leukocyte-derived PSGL-1. By contrast, it is not yet known if decoration of the identical tyrosine sulfated peptide with the triply fucosylated core 2 O-glycan is an effective P-selectin counter-receptor and the in vivo functional relevance of the multiply fucosylated isomer, if any, has yet to be defined. Additional studies will be needed to understand the stoichiometry of these modifications for each of the relevant serine/threonine residues within PSGL-1, and how heterogeneous modification may modulate binding affinities. It is worth remembering that these glycan structures were identified on HL-60 cellderived PSGL-1, and that it is not yet known if these are authentic representations of the glycan modifications on PSGL-1 in human neutrophils and other leukocytes. Similarly, virtually nothing is known about the nature of such modifications on mouse leukocytes where, as discussed below, mice with targeted deletions of the FucT-VII locus, the FucT-IV locus, and the core 2 GlcNAcT-I locus have begun to inform us about the glycosyltransferases that control E- and P-selectin counter-receptor activities.

\section{Core 2 GlcNAcT-I, PSGL-I and E- and P-selectin counter- receptor activities}

Core 2 GlcNAcT-I null mice are profoundly deficient in neutrophil P-selectin ligand activity, and P-selectin-dependent cell adhesion (58). Deficient P-selectin ligand actvity in these animals is similar to P-selectin ligand deficiencies observed in PSGL-1 null mice $(86,87)$. These studies are also consistent with the observation that reconstitution of P-selectin counterreceptor activity in cultured cell lines requires core 2 GlcNAcT activity (89-91). By contrast, it is less certain that core 2 GlcNAcT-I plays a prominent role in the elaboration of leukocyte E-selectin ligand activity. Using leukocytes from the same strain of core 2 GlcNAcT-I null mice, three studies observe defects in E-selectin counter-receptor activity that range from substantial to subtle $(58,98,99)$. These apparent discrepancies are most notable in the in vitro adhesion assays used $(58,98,99)$; as discussed in Snapp et al. (98) assay differences are likely to account for these apparent discrepancies. Studies in vivo assign a subtle contribution by core 2 GlcNAcT-I to Eselectin-dependent leukocyte rolling (99). Considered together with similar observations made with PSGL-1 null mice $(86,87)$, it can be concluded that core 2 GlcNAcT-I and PSGL1 contribute substantially less to E-selectin counter-receptor activity than to P-selectin counter-receptor activity in neutrophils. In the mouse neutrophil and in other leukocytes the precise structural nature of the glycans to which core 2 GlcNAcT-I contributes and how these may be altered in core 2 GlcNAcT-I null mice remain to be defined experimentally.

\section{Fucosylation and E- and P-selectin counter-receptor activities}

Although genetic reconstitution of E- and P-selectin counterreceptor activities in cultured cells and biochemical analyses point clearly to a requirement for $\alpha 1$-3fucosylation, these studies do not provide definitive insight into such contributions in vivo. Furthermore, such studies do not identify the $\alpha 1$-3fucosyltransferases relevant to generating E- and P-selectin ligand activity in vivo. This is an especially important issue since in the human genome there are at least six distinct $\alpha 1$-3fucosyltransferase loci encoding enzymes with potential for contributing to selectin ligand activity (FucT-III, -IV, -V, -VI, -VII, and IX) (22). To address these issues, mice have been constructed and characterized with targeted deletions of the FucT-IV and FucT-VII loci, which encode $\alpha 1$-3fucosyltransferases whose genetic and catalytic attributes and expression patterns made them probable candidates for determining $\alpha 1$-3fucosylation of the glycans relevant to leukocyte counter-receptors for E- and P-selectins $(25,59)$. These studies disclose that in mice that are homozygous for a null mutation in the FucT-VII locus, E- and P-selectin counter-receptor activities on monocytes and neutrophils are essentially absent when assessed using E- or P-selectin-IgM chimeras as flow cytometry reagents $(25,59)$. However, examination of shear-dependent adhesion of FucT-VII null neutrophils on selectin-Ig chimeras in a flow chamber identified significant residual adhesion. Residual E- and P-selectin ligand activities disclosed by the flow chamber assays were paralleled by residual leukocyte emigration in E- and P-selectindependent leukocyte recruitment assays (25). A contribution to this apparent residual E and P-selectin counter-receptor activity by FucT-IV was suspected, because this enzyme is also expressed in leukocyte progenitors (25). However, neutrophils from FucT-IV null mice exhibited essentially wild-type adhesion in vitro, and normal recruitment efficiencies in selectindependent recruitment assays in vivo. None the less, subtle increments in the rolling velocities of FucT-IV null neutrophils are 
noted when intravital microscopy is used to observe leukocyte rolling in E- and P-selectin-dependent contexts (100). These observations indicate that FucT-VII makes a prominent contribution to leukocyte E- and P-selectin ligand activities and that contributions by FucT-IV are modest when FucT-VII is present, and are subsidiary to those made by FucT-VII. To determine if a contribution by FucT-IV accounts for the residual activities observed with FucT-VII null neutrophils, mice with deficiencies in both enzymes were constructed and analyzed (25). These studies disclose that the doubly deficient neutrophils do not undergo detectable adhesive interactions with E- or P-selectins in vitro or in vivo and they are not recruited to extravascular sites in E- and P-selectin-dependent inflammatory models. It is thus possible to conclude that in mice, FucT-IV and FucT-VII collaborate to control all fucosylation events relevant to neutrophil E- and P-selectin counter-receptor activities.

FucT-VII is also expressed by Th1 and Tc1 memory-effector $\mathrm{T}$ cells derived, respectively, from naïve CD4 and CD8 lymphocytes (2,78). Th1 and Tc1 lymphocytes express Eand P-selectin counter-receptors, and are recruited to sites of cutaneous inflammation via E- and P-selectin-dependent adhesion (2,78). Th1 and Tc1 cells prepared from FucT-VII null mice do not express E- or P-selectin counter-receptor activities in vitro, and they are not recruited to acutely inflamed skin in vivo (78). By contrast, wild-type levels of E and Pselectin counter-receptor activities and in vivo trafficking efficiencies are observed with FucT-IV-deficient Th1 and Tc1 cells (78). E- and P-selectin counter-receptor activities on these lymphocyte subsets cells is thus FucT-VII-dependent, while a contribution by FucT-IV is not yet apparent. Emerging information about how selectin ligand activities are controlled in lymphocyte subsets indicates that complex, cytokine-dependent transcriptional regulation of FucT-VII, FucT-IV $(27,101,102)$ and of core 2 GlcNAcT $(27,103)$. Insight into these processes, whether inducible, as in the case of these lymphocyte subsets, or where selectin ligands are constitutively expressed, as in neutrophils and monocytes, may provide avenues for pharmacological modulation of selectin ligand activities and selectin-dependent leukocyte trafficking in inflammation.

Molecular correlates for selectin ligand-deficient phenotypes in the fucosyltransferase null mice remain to be established, and are likely to require detailed analysis of the glycan structures displayed by PSGL-1, ESL-1, glycolipids and other scaffolds on neutrophils, memory/effector lymphocytes, monocytes, eosinophils and other leukocytes.

\section{The future}

This review has used the most thoroughly studied examples of glycan-dependent control of selectin counter-receptor function and structure to help illustrate approaches and concepts relevant to understanding such processes. The review has not touched upon the many other selectin-leukocyte interactions where lineage-specific and/or dynamically regulated control of glycan structures is inferred to control selectin-dependent leukocyte trafficking and/or biology. These include L-selectin counter-receptors on vascular endothelium $(12,104)$ and on leukocytes themselves (13) that contribute to L-selectin-dependent primary and secondary capture, respectively. The repertoire of glycosyltransferases genes and cognate glycoconjugates that contribute to each of these two processes is incompletely understood and merits further study. Selectin counter-receptors are observed in specific circumstances on B lymphocytes (105), plasma cells (106), natural killer cells (107), dendritic cells (108), eosinophils (109), basophils (110), gamma-delta T lymphocytes (111), Th2 lymphocytes in vivo (112) and hematopoietic progenitors (113). In general, physiological and pathological correlates for these observations are not deeply developed, glycan structural correlates are not available, and glycosyltransferase-deficient mice are only now in use to explore these issues. Each of these systems provides opportunities for achieving a deeper understanding of how glycoconjugate biosynthetic pathways function and how they contribute to pathophysiology.

\section{References}

1. Janeway CA, Travers P, Walport M, Capra JD. Immunobiology. The immune system in health and disease, 4th edn. London: Current Biology Publications; 1999.
2. Vestweber D, Blanks JE. Mechanisms that regulate the function of the selectins and their ligands. Physiol Rev 1999;79:181213.
3. Kansas GS. Selectins and their ligands: current concepts and controversies. Blood 1996;88:3259-3287.

4. Springer TA. Traffic signals for lymphocyte recirculation and leukocyte emigration: the multistep paradigm. Cell 1994;76:301-314. 
5. Butcher EC, Picker LJ. Lymphocyte homing and homeostasis. Science 1996;272:60-66.

6. Jakob T, Ring J, Udey MC. Multistep navigation of Langerhans/dendritic cells in and out of the skin. J Allergy Clin Immunol 2001;108:688-696.

7. Harlan JM, Winn RK. Leukocyte-endothelial interactions: clinical trials of anti-adhesion therapy. Crit Care Med 2002;30:S214-S219.

8. Wagner R. Erläuterungstafeln Zur Physiologie und Entwicklungsgeschichte. Leipzig: Leopold Voss; 1839.

9. Harris ES, McIntyre TM, Prescott SM, Zimmerman GA. The leukocyte integrins. J Biol Chem 2000;275:23409-23412.

10. Eppihimer MJ, Russell J, Anderson DC, Wolitzky BA, Granger DN. Endothelial cell adhesion molecule expression in gene-targeted mice. Am J Physiol 1997;273:H1903H1908.

11. Collins T, Read MA, Neish AS, Whitley MZ, Thanos D, Maniatis T. Transcriptional regulation of endothelial cell adhesion molecules: NF-kappa B and cytokine-inducible enhancers. FASEB J 1995;9:899-909.

12. Tu L, Delahunty MD, Ding H, Luscinskas FW, Tedder TF. The cutaneous lymphocyte antigen is an essential component of the L-selectin ligand induced on human vascular endothelial cells. J Exp Med 1999;189:241252.

13. Walcheck B, Moore KL, McEver RP, Kishimoto TK. Neutrophil-neutrophil interactions under hydrodynamic shear stress involve Lselectin and PSGL-1. A mechanism that amplifies initial leukocyte accumulation of P-selectin in vitro. J Clin Invest 1996;98:10811087.

14. Kunkel EJ, Butcher EC. Chemokines and the tissue-specific migration of lymphocytes. Immunity 2002;16:1-4.

15. Sallusto F, Mackay CR, Lanzavecchia A. The role of chemokine receptors in primary, effector, and memory immune responses. Annu Rev Immunol 2000;18:593-620.

16. Rossi D, Zlotnik A. The biology of chemokines and their receptors. Annu Rev Immunol 2000;18:217-242.

17. van Kooyk Y, Figdor CG. Avidity regulation of integrins: the driving force in leukocyte adhesion. Curr Opin Cell Biol 2000;12:542-547.

18. Woodside DG, Liu S, Ginsberg MH. Integrin activation. Thromb Haemost 2001;86:316-323.

19. Luft JH. Fine structure of capillary and endocapillary layer as revealed by ruthenium red. Microcirc Symp Fed Proc 1966;25:1773-1783.

20. Pries AR, Secomb TW, Gaehtgens P. The endothelial surface layer. Pflugers Arch 2000:440:653-666.
21. Varki A, Cummings R, Esko J, Freeze H, Hart G, Marth J, eds. Essentials of glycobiology. New York: Cold Spring Harbor Laboratory Press; 1999.

22. Taniguchi N, Honke K, Fukuda M. Handbook of glycosyltransferases and related genes. New York: Springer; 2002.

23. Manzella SM, Hooper LV, Baenziger JU. Oligosaccharides containing beta 1,4-linked $\mathrm{N}$-acetylgalactosamine, a paradigm for protein-specific glycosylation. J Biol Chem 1996;271:12117-12120.

24. Hiraoka N, et al. A novel, high endothelial venule-specific sulfotransferase expresses 6sulfosialyl Lewis (x), an L-selectin ligand displayed by CD34. Immunity 1999;11:7989.

25. Homeister JW, et al. The alpha $(1,3)$ fucosyltransferases FucT-IV and FucT-VII exert collaborative control over selectin-dependent leukocyte recruitment and lymphocyte homing. Immunity 2001;15:115-126.

26. Huang MC, et al. P-selectin glycoprotein ligand-1 and E-selectin ligand-1 are differentially modified by fucosyltransferases FucTIV and Fuc-TVII in mouse neutrophils. J Biol Chem 2000;275:31353-31360.

27. White SJ, Underhill GH, Kaplan MH, Kansas GS. Cutting edge: differential requirements for Stat4 in expression of glycosyltransferases responsible for selectin ligand formation in Th1 cells. J Immunol 2001;167:628631.

28. Skrincosky D, Kain R, El-Battari A, Exner M, Kerjaschki D, Fukuda M. Altered Golgi localization of core 2 beta-1,6-N-acetylglucosaminyltransferase leads to decreased synthesis of branched O-glycans. J Biol Chem 1997;272:22695-22702.

29. Keppler OT, Hinderlich S, Langner J, Schwartz-Albiez R, Reutter W, Pawlita M. UDP-GlcNAc 2-epimerase: a regulator of cell surface sialylation. Science 1999;284:1372-1376.

30. Stamper HB Jr, Woodruff JJ. An in vitro model of lymphocyte homing. I. Characterization of the interaction between thoracic duct lymphocytes and specialized high-endothelial venules of lymph nodes. J Immunol 1977;119:772-780.

31. Gallatin WM, Weissman IL, Butcher EC. A cell-surface molecule involved in organspecific homing of lymphocytes. Nature 1983;304:30-34

32. Arbones ML, et al. Lymphocyte homing and leukocyte rolling and migration are impaired in L-selectin-deficient mice. Immunity $1994 ; \mathbf{1}: 247-260$.

33. Xu J, Grewal IS, Geba GP, Flavell RA. Impaired primary $\mathrm{T}$ cell responses in L-selectindeficient mice. J Exp Med 1996;183:589598.
34. Stoolman LM, Rosen SD. Possible role for cell-surface carbohydrate-binding molecules in lymphocyte recirculation. J Cell Biol 1983;96:722-779.

35. Stoolman LM, Tenforde TS, Rosen SD. Phosphomannosyl receptors may participate in the adhesive interaction between lymphocytes and high endothelial venules. J Cell Biol 1984;99:1535-1540.

36. Rosen SD, Singer MS, Yednock TA, Stoolman LM. Involvement of sialic acid on endothelial cells in organ-specific lymphocyte recirculation. Science 1985;228:1005-1007.

37. Rosen SD, Chi S-I, True DD, Singer MS, Yednock TA. Intravenously injected sialidase inactivates attachment sites for lymphocytes on high endothelial venules. J Immunol 1989;142:1895-1902.

38. Watson SR, Imai Y, Fennie C, Geoffroy J, Rosen SD, Lasky LA. A homing receptorIgG chimera as a probe for adhesive ligands of lymph node high endothelial venules. J Cell Biol 1990;110:2221-2229.

39. Imai Y, Sinfer MS, Fennie C, Lasky LA, Rosen SD. Identification of a carbohydrate-based endothelial ligand for a lymphocyte homing receptor. J Cell Biol 1991;113:1213-1221.

40. Imai Y, Lasky LA, Rosen SD. Sulphation requirement for GlyCAM-1, an endothelial ligand for L-selectin. Nature 1993;361:555-557.

41. Lasky LA, et al. An endothelial ligand for Lselectin in a novel mucin-like molecule. Cell 1992;69:927-938.

42. Schleiffenbaum B, Spertini O, Tedder TF. Soluble L-selectin is present in human plasma at high levels and retains functional activity. J Cell Biol 1992;119:229-238.

43. Baumhueter S, et al. Binding of L-selectin to the vascular sialomucin CD34. Science 1993;262:436-442.

44. Cheng J, et al. Hematopoietic defects in mice lacking the sialomucin CD34. Blood 1996;87:479-490.

45. Berg EL, McEvoy LM, Berli C, Bargatze RF, Butcher EC. L-selectin mediated lymphocyte rolling on MAdCAM-1. Nature 1993;366:695-698.

46. Sassetti C, Tangemann K, Singer MS, Kershaw DB, Rosen SD. Identification of podocalyxin-like protein as a high endothelial venule ligand for L-selectin: parallels to CD34. J Exp Med 1998;187:1965-1975.

47. Berg EL, Magnani J, Warnock RA, Robinson MK, Butcher EC. Comparison of L-selectin and E-selectin ligand specificities: the L-selectin can bind to the E-selectin ligands sialyl Le ${ }^{\mathrm{x}}$ and sialyl Le $\mathrm{Le}^{\mathrm{a}}$. Biochem Biophys Res Commun 1992;184:1048-1055. 
48. Foxall C, et al. The three members of the selectin receptor family recognize a common carbohydrate epitope, the sialyl Lewis $\times$ oligosaccharide. J Cell Biol 1992;4:895902.

49. Green PJ, et al. High affinity binding of leukocyte adhesion molecule L-selectin to $3^{\prime}$-sulphated-Le ${ }^{\mathrm{a}}$ and $-\mathrm{Le}^{\mathrm{x}}$ oligosaccharides and the predominance of sulphate in this interaction demonstrated by binding studies with a series of lipid-linked oligosaccharides. Biochem Biophys Res Commun 1992;188:244-251.

50. Hemmerich S, Bertozzi CR, Leffler H, Rosen SD. Identification of the sulfated monosaccharides of GlyCAM-1, an endothelial-derived ligand for L-selectin. Biochemistry 1994;33:4820-4829.

51. Hemmerich S, Rosen SD. 6'-Sulfated sialyl Lewis $\mathrm{x}$ is a major capping group of GlyCAM1. Biochemistry 1994;33:4830-4835.

52. Crommie D, Rosen SD. Biosynthesis of GlyCAM-1, a mucin-like ligand for L-selectin. J Biol Chem 1995;270:22614-22624.

53. Hemmerich S, Leffler H, Rosen SD. Structure of the O-glycans in GlyCAM-1, an endothelial-derived ligand for L-selectin. J Biol Chem 1995;270:12035-12047.

54. Mitsuoka C, et al. Identification of a major carbohydrate capping group of the L-selectin ligand on high endothelial venules in human lymph nodes as 6-sulfosialyl Lewis x. J Biol Chem 1998;273:11225-11233.

55. Bistrup A, et al. Sulfotransferases of two specificities function in the reconstitution of high endothelial cell ligands for L-selectin. J Cell Biol 1999;145:899-910.

56. Hiraoka N, et al. A novel, high endothelial venule-specific sulfotransferase directs expression of 6-sulfosialyl Lewis $\mathrm{x}$, an L-selectin ligand displayed by CD34. Immunity 1999;11:79-89.

57. Kimura N, et al. Reconstitution of functional 1-selectin ligands on a cultured human endothelial cell line by cotransfection of 1-3 fucosyltransferase VII and newly cloned GlcNAc: 6-sulfotransferase cDNA. Proc Natl Acad Sci USA 1999;96:4530-4535.

58. Ellies LG, Tsuboi S, Petryniak B, Lowe JB, Fukuda M, Marth JD. Core 2 oligosaccharide biosynthesis distinguishes between selectin ligands essential for leukocyte homing and inflammation. Immunity 1998;9:881890.

59. Maly P, et al. The $\alpha(1,3)$ fucosyltransferase Fuc-TVII controls leukocyte trafficking through an essential role in L-, E-, and Pselectin ligand biosynthesis. Cell 1996;86:643-653.
60. Hemmerich S, et al. Sulfation of 1-selectin ligands by an HEV-restricted sulfotransferase regulates lymphocyte homing to lymph nodes. Immunity 2001;15:237-247.

61. Hemmerich S, Rosen SD. Carbohydrate sulfotransferases in lymphocyte homing. Glycobiology 2002;10:849-856.

62. Torii T, Fukuta M, Habuchi O. Sulfation of sialyl N-acetyllactosamine oligosaccharides and fetuin oligosaccharides by keratan sulfate Gal-6-sulfotransferase. Glycobiology 2000;10:203-211.

63. Habuchi O, Suzuki Y, Fukuta M. Sulfation of sialyl lactosamine oligosaccharides by chondroitin 6-sulfotransferase. Glycobiology 1997;7:405-412.

64. Hemmerich S, Lee JK, Bhakta S, Bistrup A, Ruddle NR, Rosen SD. Chromosomal localization and genomic organization for the galactose/N-acetylgalactosamine/Nacetylglucosamine 6-O-sulfotransferase gene family. Glycobiology 2001;11:75-87.

65. Tangemann K, Bistrup A, Hemmerich S, Rosen SD. Sulfation of a high endothelial venule-expressed ligand for L-selectin. Effects on tethering and rolling of lymphocytes. J Exp Med 1999;190:935-942.

66. Bargatze RF, Jutila MA, Butcher EC. Distinct roles of L-selectin and integrins alpha 4 beta 7 and LFA- 1 in lymphocyte homing to Peyer's patch-HEV in situ: the multistep model confirmed and refined. Immunity 1995;3:99-108.

67. Fukuta M, Inazawa J, Torii T, Tsuzuki K, Shimada E, Habuchi O. Molecular cloning and expression of chick chondrocyte chondroitin 6-sulfotransferase. J Biol Chem 1995;270:18575-18580.

68. Fukuta M, Inazawa J, Torii T, Tsuzuki K, Shimada E, Habuchi O. Molecular cloning and characterization of human keratan sulfate Gal-6-sulfotransferase. J Biol Chem 1997;272:32321-32328.

69. Uchimura K, et al. Molecular cloning and characterization of an $\mathrm{N}$-acetylglucosamine-6-O-sulfotransferase. J Biol Chem 1998;273:22577-22583.

70. Lee JK, Bhakta S, Rosen SD, Hemmerich S. Cloning and characterization of a mammalian N-acetylglucosamine-6-sulfotransferase that is highly restricted to intestinal tissue. Biochem Biophys Res Commun 1999;263:543-549.

71. Kitagawa H, Fujita M, Itio N, Sugahara K. Molecular cloning and expression of a novel chondroitin 6-O-sulfotransferase. J Biol Chem 2000;275:21075-21080.

72. Bhakta S, et al. Sulfation of N-acetylglucosamine by chondroitin 6-sulfotransferase 2 (GST-5). J Biol Chem 2000;275:4022640234 .
73. Yeh JC, Ong E, Fukuda M. Molecular cloning and expression of a novel beta-1, 6-N-acetylglucosaminyltransferase that forms core 2, core 4 , and I branches. J Biol Chem 1999;274:3215-3221.

74. Schwientek T, et al. Control of O-glycan branch formation. Molecular cloning and characterization of a novel thymus-associated core 2 beta 1,6-n-acetylglucosaminyltransferase. J Biol Chem 2000;275:1110611113.

75. Yeh JC, et al. Novel sulfated lymphocyte homing receptors and their control by a Core 1 extension beta 1,3-N-acetylglucosaminyltransferase. Cell 2001;105:957-969.

76. Zhou D, et al. A beta-1,3-N-acetylglucosaminyltransferase with poly-N-acetyllactosamine synthase activity is structurally related to beta-1,3-galactosyltransferases. Proc Natl Acad Sci USA 1999;96:406-411.

77. Smith PL, et al. Expression of the alpha $(1,3)$ fucosyltransferase Fuc-TVII in lymphoid aggregate high endothelial venules correlates with expression of L-selectin ligands. J Biol Chem 1996;271:8250-8259.

78. Smithson G, et al. Fuc-TVII is required for T helper 1 and $\mathrm{T}$ cytotoxic 1 lymphocyte selectin ligand expression and recruitment in inflammation, and together with Fuc-TIV regulates naive $\mathrm{T}$ cell trafficking to lymph nodes. J Exp Med 2001;194:601-614.

79. Bradley LM, Watson SR, Swain SL. Entry of naive CD4 T cells into peripheral lymph nodes requires L-selectin. J Exp Med 1994; 180:2401-2406.

80. Singer MS, Rosen SD. Purification and quantification of L-selectin-reactive GlyCAM1 from mouse serum. J Immunol Meth 1996;96:153-161.

81. Galustian C, Lubineau A, le Narvor C, Kiso M, Brown G, Feizi T. L-selectin interactions with novel mono- and multisulfated Lewis $\mathrm{x}$ sequences in comparison with the potent ligand 3'-sulfated Lewis a. J Biol Chem 1999;274:18213-18217.

82. Stroud MR, et al. Monosialogangliosides of human myelogenous leukemia HL60 cells and normal human leukocytes. 2. Characterization of E-selectin binding fractions, and structural requirements for physiological binding to E-selectin. Biochemistry 1996;35:770-778.

83. Picker LJ, Warnock RA, Burns AR, Doerschuk CM, Berg EL, Butcher EC. The neutrophil selectin LECAM-1 presents carbohydrate ligands to the vascular selectins ELAM-1 and GMP-140 [erratum appears in Cell 1991;67:1267]. Cell 1991;66:921-933.

84. Zollner O, et al. L-selectin from human, but not from mouse neutrophils binds directly to E-selectin. J Cell Biol 1997;136:707-716. 
85. Steegmaier M, et al. The E-selectin-ligand ESL-1 is a variant of a receptor for fibroblast growth factor. Nature 1995;373:615-620.

86. Xia L, et al. P-selectin glycoprotein ligand1-deficient mice have impaired leukocyte tethering to E-selectin under flow. J Clin Invest 2002;109:939-950.

87. Yang J, et al. Targeted gene disruption demonstrates that P-selectin glycoprotein ligand 1 (PSGL-1) is required for P-selectin-mediated but not E-selectin-mediated neutrophil rolling and migration. J Exp Med 1999;190:1769-1782.

88. Moore KL, et al. Identification of a specific glycoprotein ligand for P-selectin (CD62) on myeloid cells. J Cell Biol 1992;118:445456.

89. Sako D, et al. Expression cloning of a functional glycoprotein ligand for P-selectin. Cell 1993;75:1179-1186.

90. Li F, Wilkins PP, Crawley S, Weinstein J, Cummings RD, McEver RP. Post-translational modifications of recombinant P-selectin glycoprotein ligand-1 required for binding to Pand E-selectin. J Biol Chem 1996;271:3255-3264.

91. Wilkins PP, Moore KL, McEver RP, Cummings RD. Tyrosine sulfation of P-selectin glycoprotein ligand-1 is required for high affinity binding to P-selectin. J Biol Chem 1995;270:22677-22680.

92. Pouyani T, Seed B. PSGL-1 recognition of Pselectin is controlled by a tyrosine sulfation consensus at the PSGL-1 amino terminus. Cell 1995;83:333-343.

93. Somers WS, Tang J, Shaw GD, Camphausen RT. Insights into the molecular basis of leukocyte tethering and rolling revealed by structures of P- and E-selectin bound to SLe (X) and PSGL-1. Cell 2000;103:467-479.

94. Ouyang Y, Lane WS, Moore KL. Tyrosylprotein sulfotransferase: purification and molecular cloning of an enzyme that catalyzes tyrosine O-sulfation, a common posttranslational modification of eukaryotic proteins. Proc Natl Acad Sci USA 1998;95:2896-2901.
95. Ouyang YB, Crawley JT, Aston CE, Moore $\mathrm{KL}$. Reduced body weight and increased postimplantation fetal death in tyrosylprotein sulfotransferase- 1 deficient mice. J Biol Chem 2002;in press.

96. Wilkins PP, McEver RP, Cummings RD. Structures of the O-glycans on P-selectin glycoprotein ligand-1 from HL-60 cells. J Biol Chem 1996;271:18732-18742.

97. Leppanen A, et al. A novel glycosulfopeptide binds to P-selectin and inhibits leukocyte adhesion to P-selectin. J Biol Chem 1999;274:24838-24848.

98. Snapp KR, Heitzig CE, Ellies LG, Marth JD, Kansas GS. Differential requirements for the O-linked branching enzyme core 2 beta 1-6$\mathrm{N}$-glucosaminyltransferase in biosynthesis of ligands for E-selectin and P-selectin. Blood 2001;97:3806-3811.

99. Sperandio M, Thatte A, Foy D, Ellies LG, Marth JD, Ley K. Severe impairment of leukocyte rolling in venules of core 2 glucosaminyltransferase-deficient mice. Blood 2001;97:3812-3819.

100. Weninger $\mathrm{W}$, et al. Specialized contributions by alpha $(1,3)$-fucosyltransferase-IV and FucT-VII during leukocyte rolling in dermal microvessels. Immunity 2000;12:665-676

101. Lim YC, Henault L, Wagers AJ, Kansas GS, Luscinskas FW, Lichtman AH. Expression of functional selectin ligands on Th cells is differentially regulated by IL-12 and IL-4. J Immunol 1999;162:3193-33201.

102. Wagers AJ, Kansas GS. Potent induction of alpha $(1,3)$-fucosyltransferase VII in activated $\mathrm{CD} 4+\mathrm{T}$ cells by TGF-beta 1 through a p38 mitogen-activated protein kinase-dependent pathway. J Immunol 2000; 165:5011-5016.

103. Lim YC, et al. IL-12, STAT4-dependent upregulation of CD4 (+) T cell core 2 beta-1,6n-acetylglucosaminyltransferase, an enzyme essential for biosynthesis of P-selectin ligands. J Immunol 2001;167:4476-4484.
104. Sperandio M, Forlow SB, Thatte J, Ellies LG, Marth JD, Ley K. Differential requirements for core2 glucosaminyltransferase for endothelial L-selectin ligand function in vivo. J Immunol 2001;167:2268-2274.

105. Montoya MC, et al. Memory B lymphocytes from secondary lymphoid organs interact with E-selectin through a novel glycoprotein ligand. J Clin Invest 1999;103:1317-1327.

106. Underhill GH, Minges-Wols HA, Fornek JL, Witte PL, Kansas GS. IgG plasma cells display a unique spectrum of leukocyte adhesion and homing molecules. Blood 2002;99:2905-2912.

107. Yago T, et al. IL-12 promotes the adhesion of NK cells to endothelial selectins under flow conditions. J Immunol 1998;161:1140-1145.

108. Pendl GG, et al. Immature mouse dendritic cells enter inflamed tissue, a process that requires E- and P-selectin, but not P-selectin glycoprotein ligand-1. Blood 2002;99:946-956.

109. Edwards BS, Curry MS, Tsuji H, Brown D, Larson RS, Sklar LA. Expression of P-selectin at low site density promotes selective attachment of eosinophils over neutrophils. J Immunol 2000;165:404-410.

110. Taylor ML, Brummet ME, Hudson SA, Miura $\mathrm{K}$, Bochner BS. Expression and function of P-selectin glycoprotein ligand 1 (CD162) on human basophils. J Allergy Clin Immunol 2000;106:918-924.

111. Jutila MA, et al. Cell surface P- and E-selectin support shear-dependent rolling of bovine gamma/delta $T$ cells. J Immunol 1994;153:3917-3928.

112. Tietz $\mathrm{W}$, et al. CD4+ T cells migrate into inflamed skin only if they express ligands for E- and P-selectin. J Immunol 1998;161:963-970.

113. Levesque JP, et al. PSGL-1-mediated adhesion of human hematopoietic progenitors to P-selectin results in suppression of hematopoiesis. Immunity 1999;11:369-378. 